\title{
A DIMENSÃO PÚBLICA DA SUBJETIVIDADE EM TEMPOS DE ORKUT
} THE PUBLIC DIMENSION OF SUBJECTIVITY IN ORKUT DAYS

\author{
Carla Neves e Francisco Teixeira Portugal \\ Universidade Federal do Rio de Janeiro, Rio de Janeiro, Brasil
}

\section{RESUMO}

Partindo da presença garantida das novas tecnologias de comunicação na vida cotidiana, procura-se, no presente artigo investigar os efeitos subjetivos relacionados à comunidade online do Orkut e às experiências sociais contemporâneas. O trabalho estabelece um diálogo com os estudos de autores como Latour, Callon e Law, principalmente no que se refere ao conceito de rede sociotécnica ou de coletivo e à noção de mediação entendida como tradução, para, a partir daí, pensar os objetos técnicos como um dos muitos elementos que participam ativamente do processo de produção de diferentes modos de sociabilidade e de subjetivação. Por meio do levantamento e da análise das comunidades do Orkut que tem como temática o próprio site, procurou-se elucidar seus efeitos e deslocamentos, travando uma reflexão sobre o regime de visibilidade da subjetividade e o movimento atual de publicização de si.

Palavras-chave: comunidade online; mediação; Orkut; público; subjetividade.

\begin{abstract}
Based on the presence of new communication technologies in everyday life, this article investigates the subjective effects related to the online community Orkut and the contemporary social experiences. This work establishes a dialogue with the studies of authors such as Latour, Callon and Law, especially regarding the concept of collective or social network and the concept of mediation as translation, and from this point observe technical objects as one of many other elements that actively participate in the production process of different ways of sociability and subjectivity. Through surveys and analysis on communities inside Orkut that have as theme the site itself, we tried to elucidate the effects and displacements stopping at the reflection on the regimes of visibility of subjectivity and the current movement of self-advertisement.
\end{abstract}

Keywords: online community; mediation; Orkut; public; subjectivity.

\section{O Espaço Comum Contemporâneo}

As mensagens dependem, mais do que julgamos, dos canais que as transmitem (Serres, 1994, p. 172)

Desde sua criação, a rede interconectada de computadores, ultrapassou o círculo acadêmico e se transformou em uma poderosa tecnologia de uso pessoal. Mais que isso, a Internet se traduz atualmente em mais um espaço cotidiano de sociabilidade. A contemporânea e inevitável composição entre a tecnologia digital e as interações sociais abarca uma gama variada de espaços de troca, que vão desde os correios eletrônicos (e-mails), passando pelas salas de bate-papo ( $\underline{\text { chats }})$, os programas de mensagens instantâneas (MSN, Google Talk), até chegar nas chamadas comunidades online (Orkut, MySpace, Facebook). Partindo da constatação da massiva presença das novas tecnologias de comunicação na vida cotidiana, procura-se, no presente artigo, investigar os efeitos subjetivos da composição contemporânea que relaciona os objetos técnicos e as experiências sociais.

O Orkut ${ }^{1}$, nosso objeto de estudo, é o que se denomina uma comunidade virtual. $\mathrm{O}$ site tem como objetivo criar um espaço online de encontro "onde é possível fazer novos amigos, conhecer pessoas com os mesmos interesses e estabelecer seu círculo social" ${ }^{\prime 2}$. Diante do modismo e de sua rápida disseminação no Brasil, a comunidade reúne hoje milhões de participantes. Assim como a linguagem http da $\underline{W e b}$ cria um espaço onde é possível se perder navegando em um mar de informações; o sítio da comunidade, na mesma lógica de funcionamento, nos permite transitar por uma multidão de pessoas que assumem forma em suas páginas pessoais (os chamados perfis ou profiles).

Referido as redes sociais digitais, o uso atual do termo "comunidade" surge na esteira do processo de globalização. Uso que não nega ou contradiz o movi- 
mento extensivo de interdependência global, mas reafirma o movimento, subvertendo o sentido tradicional do termo. Sawaia (2007) aponta o quanto a apropriação contemporânea escapa aos valores e definições da sociologia emergente do século XIX. Momento em que a noção de comunidade elevou-se à categoria analítica central do pensamento social, e se estabeleceu a antítese entre comunidade e sociedade como expressão do contraste entre valores comunitários e individualistas, respectivamente.

A versão contemporânea de comunidade não se opõe, como outrora, ao processo de individualização, de valorização da liberdade pessoal e aos preceitos racionalistas característicos da sociedade moderna. Por um lado, as configurações atuais se fundam em questões outras que não a coesão, a proximidade local, a homogeneidade e a existência de objetivos comuns. O que acaba por levar ao caráter líquido dos laços sociais pós-modernos, no qual a durabilidade, a reciprocidade e a proximidade das relações sociais são reconfiguradas. Transformações que também afetam os valores e a qualidade dos vínculos sociais (Bauman, 2001, 2005).

No conjunto das transformações contemporâneas, as novas tecnologias de comunicação assumem o papel de desestabilizadores da tradição dicotômica moderna, complexificando e reconfigurando sua organização. $\mathrm{O}$ tempo das comunicações rompe com as fronteiras modernas entre dentro e fora, misturando local e global, proximidade e distância, privacidade e publicidade. Recuero $(2001,2002)$ e Lemos (2002) propõem que comunidades virtuais, como o Orkut, se diferenciam das outras modalidades de comunicação mediada por computador ao estabelecerem uma forma de relação regular e contato contínuo entre os internautas, criando, assim, um contexto ou lócus comum de troca.

Embora seja tentador pensar "comunidade" como um conceito que se refere à segurança e ao aconchego, a proposta é afirmá-la como lugar de encontro, na medida em que pressupõe o deparar-se com o diferente. Para além da mesmidade e da homogeneidade, o espaço comum de troca se faz pela multiplicidade, reconhecido como um espaço que se constitui a partir das ações relacionais de comunicação entre aqueles que o compõem (Jovchelovitch, 2008).

No diálogo com autores como Callon e Law (1997), Law (1992) e Latour (1994a, 1994b); o espaço comum pode ser entendido como uma rede sociotécnica ou como um coletivo, conceito que reside no núcleo da Teoria Ator-Rede. A condição de ator se refere a tudo que age deixando traço no mundo, podendo ser referido a pessoas, instituições, coisas, animais, objetos, máquinas. Elementos heterogêneos que produzem efeito na rede, que a modificam e são modificados pela mesma. A ideia de coletivo entendido como uma rede sociotécnica escapa à dicotomia sujeito-objeto, indivíduo-sociedade, e pressupõe o foco no campo das relações. Campo onde a ação se encontra distribuída na multiplicidade e diversidade de elementos associados que participam de sua composição. Evidencia a heterogeneidade ao mesmo tempo em que autoriza a pensar os objetos técnicos como agentes no processo de construção da realidade.

Ao colocar tanto sujeito quanto objeto no mesmo plano de análise, a Teoria Ator-Rede afirma o campo das relações (a rede) como o lugar de produção das entidades. Suas proposições assumem, assim, um caráter ontológico que possibilita alcançar a dimensão constitutiva dos seres e das coisas, lugar de produção das subjetividades. Tal movimento de produção é o que Latour denomina mediação ou tradução. Conceito utilizado para designar deslocamento ou invenção, isto é, a criação de uma ligação que não existia antes, e que em algum nível modifica os elementos ou agentes do quadro de ação considerado.

Seguindo as postulações de Latour (1994a, 1994b), o processo de mediação produzido pelas novas tecnologias não é menor e nem se define pela oposição direta às experiências imediatas dos corpos presentes. Como afirma Serres (1999), as interações sociais estão, hoje, cada vez mais fundadas no espaço de circulação e troca dos bens imateriais. Fundadas no lugar da representação e do conhecimento, os novos modos de relação mediada não perdem seu caráter de realidade, reduzidos ao espetáculo, à artificialidade, à superficialidade e à teatralização: "Como acusar de "falta de realidade" a esfera midiática se ela põe em cena uma multiplicidade de dispositivos sociotécnicos que, ao operarem as mediações, estreitam nosso contato com o real?" (Latour, 1997). O movimento de mediação, entendido aqui como criação, se encontra na base da dinâmica do coletivo, ele produz uma experiência efetivamente vivida pelos indivíduos. Experiência a partir da qual, cotidianamente, os elementos envolvidos se constroem, desconstroem e se reconstroem simultaneamente.

Nesse sentido, pensando a rede comunitária do Orkut como um ponto - um elemento ativo no coletivo -, propõe-se analisar a relação de mediação e explorar as possíveis realizações subjetivas, tomando como campo investigativo o próprio site.

\section{O Orkut Pelo Orkut}

A aliança com a Teoria Ator-Rede abre tanto o campo de problematização sobre o Orkut como também guia os caminhos metodológicos de investigação do objeto. Entendido como um elemento ativo na dinâmica coletiva, o trabalho pretende dar voz ao objeto técnico e fazê-lo falar por si mesmo. Na busca de um material elucidativo e vivo optou-se por explorar as comunidades de dentro 
do Orkut que são referidas ao próprio site. A discussão se baseia, principalmente, na articulação teórico-conceitual posta em confronto com as questões e temáticas levantadas empiricamente pelo material coletado.

As comunidades do Orkut são criadas pelos próprios membros da rede e funcionam como fóruns de interesse comum. Por meio deste dispositivo de discussão e reunião, os participantes podem expor opiniões, trocar informações e experiências referidas a um tema específico, delimitado pelo título e pela descrição da comunidade. A partir da ferramenta de busca do site, foram coletadas comunidades que têm o Orkut como tema principal de discussão - profícuo material de elucidação dos modos pelos quais o espaço online de troca foi apropriado, apontando usos, sentidos, funções e efeitos.

Sendo assim, num primeiro momento as comunidades foram organizadas em dois grupos. O primeiro grupo se refere às comunidades que expressam o modo de relação que os membros estabelecem com o Orkut. Ele diz respeito às práticas suscitadas, usos e sentidos delegados na relação sujeito-objeto técnico. No segundo grupo de comunidades, foram organizadas aquelas que tomam o Orkut como ator social, ocasião em que ele aparece como sujeito de uma ação no sentido gramatical. Tais comunidades clareiam os efeitos ou deslocamentos produzidos pelo site. Ou seja, os desdobramentos da relação de composição entre o sujeito e o objeto tecnológico.

O atravessamento entre os domínios público e privado emerge então como fenômeno de destaque nas questões referidas aos usos e às relações entre os pares. O movimento de abertura e publicização de si, promovido pelas ferramentas do Orkut, trazem como tema de reflexão as negociações entre visibilidade e autenticidade, produção e reprodução, fato e feito. Efeitos da mediação que dizem respeito a uma impossibilidade de fechamento autêntico e fidedigno da unidade de si e a um inevitável movimento de traição, tal como postulado por Law $(1992,1999)$ e Latour (2004).

\section{O movimento de publicização de si}

Eu acho que o orkut é como se fosse uma rua de antigamente, de cidade pequena... vc "encontra" as pessoas, visita a "casa" delas ou só passa na porta sem deixar recado e sabe da vida de todo mundo. E assim como na rua vc controla a informação que torna pública, vc pode fazer isso no orkut tb, pq não? A rua também é pública e nem por isso a gente expõe tudo sobre nós mesmos. A gente controla, filtra... uns mais e outros menos.

Tal como apontado pela fala de um dos participantes da comunidade O Orkut pelo Orkut, a comunidade do Orkut se configuraria como uma expressão contemporânea de espaço público. Quando a comunicação que se faz de todos para todos, tudo ou quase tudo o que acontece é passível de verificação e conhecimento por todos os que dela participam. "Um dos aspectos mais importantes da vida em comunidade é que ela cria uma esfera pública" (Jovchelovitch, 2008, p.147). Entretanto, o espaço comum é sempre definido pelas ações relacionais entre os envolvidos. Por meio da comunicação, os membros definem a forma de esfera pública que lhe é peculiar: o modo de relação, a qualidade dos conteúdos que ali circulam, tanto quanto suas fronteiras podem ser dos mais diferentes tipos (Jovchelovitch, 2008). A discussão sobre a esfera pública tem uma longa história no pensamento social e político ocidental. Para explorar tal concepção, é frequente que autores se reportem aos debates filosóficos sobre a Grécia Clássica e à vida da polis, quando os cidadãos se reuniam para discutir as questões de interesse coletivo e criar uma ordem social orientada para o bem comum (Constant, 1814/1985; Thompson, 1998; Vernant, 1968).

Mas é ao longo da modernidade que a esfera privada passa a assumir um papel cada vez mais relevante na organização social, e se constitui em oposição direta aos modos de experienciar a vida pública. É neste período histórico que o termo se aproxima do uso atual, referindo-se ao que está aberto à observação de qualquer pessoa, enquanto o privado configura-se como referido a uma região protegida da vida pública, constituída principalmente pelas relações pessoais centradas na família.

$\mathrm{Na}$ medida em que facilita o acesso e a localização, o site e suas ferramentas promovem o encontro entre uma diversidade de conhecidos e desconhecidos. Permite ao sujeito construir seu círculo social, agregando e reunindo velhos e novos amigos num espaço comum de troca e expressão de afeto, movimento que pode ser visto em comunidades como: Reencontrei amigos no orkut (19.555 membros); Achei a galera graças ao Orkut (34.776 membros); To achando todo mundo no orkut (5.238 membros); Desenterrei cada ser no orkut! (10.140 membros); Minha Família Inteira no Orkut (7.788 membros).

O global assume seu caráter comunitário, na medida em que atualiza em um espaço comum o distante no tempo e no espaço, viabilizando associações, independente dos limites impostos pela distância física dos corpos. A partir da circulação entre páginas e links, é possível aos membros explorar suas identidades mútuas e construir conhecimento e reconhecimento do outro. É o caso de: Acho q já te vi no orkut! . $^{3}\left(21.574\right.$ membros) ${ }^{4}$ descrita como "Então... vc vê na escola, na rua, numa balada e pensa: "já vi essa pessoa no orkut", e de: Te conheço do Orkut! (19.427 membros). Marcadas pela mul- 
tiplicidade, Jovchelovitch (2008) afirma que, ao mesmo tempo em que as comunidades geram a experiência de pertença, são responsáveis por fornecer ao indivíduo o seu referencial identitário. Entre o deslocamento e a orientação, o site pode ser entendido como mais um componente do 'estojo de identidade' do eu (Goffman, 2005 , p. 28). Retratado na definição da comunidade Guio minha vida pelo orkut (273 membros):

Comunidade para pessoas que vivem em função do orkut..." "Voltar pra você? Mas nem pensar! Já coloquei "solteiro(a)" no meu perfil..." "Desculpe o atraso, não ouvi o despertador de o meu celular tocar... É que não estou mais dormindo com ele do meu lado. Queria sair daquela comunidade...". "Comprei uma passagem para Recife pra minha irmã! Agora já posso entrar na comunidade!! :D”

Apesar da ideia inicial de criar um espaço comum para debate, um fórum de discussão, o material coletado na ferramenta de busca do Orkut demonstra este outro modo de uso que se fez das comunidades do site. $\mathrm{Na}$ tentativa de responder a pergunta "quem sou eu", antes de se tornarem um meio de agregar iguais e pertencer a um grupo de pessoas com os mesmos interesses, as comunidades transformaram-se, acima de tudo, em um meio, criativo e expressivo, de falar sobre si e de afirmar a personalidade individual. Em sintonia com a necessidade de afirmação da singularidade dos membros, pululam no site as comunidades que têm como referência a primeira pessoa: Eu amo Chocolate! (2.519.685 membros); Eu Odeio Acordar Cedo (4.065.615 membros); Eu amo fim de semana (4.369.002 membros); Eu falo sozinho! (740.168 membros).

$\mathrm{Na}$ busca de se fazer representar como um nó na rede, as comunidades - agora compostas por milhões de desconhecidos - se tornaram uma extensão do perfil do usuário, assumindo um caráter identitário ${ }^{5}$. Expressam questões particulares de cada um, como: valores, sentimentos, posições políticas, preferências pessoais e opiniões sobre os mais diversos assuntos da vida cotidiana. O que é facilmente visualizado em Minhas comunidades me revelam (229.109 membros):

Já parou pra pensar que as suas comunidades revelam muito sobre Você? Pois é... revelam e muito! Muitas pessoas, quando vão adicionar outras em sua lista de amigos olham as comunidades dessa pessoa para ver um pouco de sua personalidade!!!... o importante é mostrar como somos de fato, quem gostar de você, será do jeito que você é... [grifo nosso]

Ou então, em $O$ que te descreve é comunidade (3.434 membros): "Para quem acredita que o perfil não descreve tão bem a personalidade, quanto às comunidades. Elas sim, dizem exatamente como nós somos. Se você também pensa dessa forma, seu lugar é aqui!" [grifo nosso].
Muitos são os autores que exploram o processo de delimitação das diferenças entre as dimensões de público e privado, e sua função na experiência social ao longo da modernidade (Constant, 1814/1985; Simmel, 1973; Thompson, 1998; Chartier, 1991; Sennet, 1998). Os estudos historiográficos de Chartier (1991) demonstram como "as novas modalidades de relação com a escrita, constroem, entre os séculos XVI e XVIII, uma esfera da intimidade, um retiro e refúgio para o indivíduo subtraído aos controles da vida pública em comunidade" (Chartier, 1991, p. 113). Já Constant (1814/1985) estabelece a relação entre o surgimento de um sistema político representativo e a valorização cada vez maior da esfera privada, do lugar do direito e da liberdade individual que se faz independente do exercício político. Quando o comércio, o crédito e o cálculo das cidades modernas inspiram nos homens um forte amor pela independência individual, atendem a suas necessidades e satisfazem seus desejos sem a intervenção da autoridade.

Sentido também levantado por Thompson (1998), que teria emergido no discurso sociopolítico ocidental moderno. Sentido no qual o público passa a significar aberto ou acessível a todos. Aquilo que é visível ou observável, o que é realizado na frente de outros, o que está aberto para que todos ou muitos vejam ou ouçam. O privado, de forma antagônica, se referiria ao que se esconde da vista dos outros, ao que é dito ou feito em privacidade, ou em segredo, ou em um círculo restrito de pessoas. Permanecendo ainda com o autor, a dicotomia reconfigura-se em publicidade versus privacidade, em abertura versus segredo, em visibilidade versus invisibilidade.

Sennett (1998) propõe que, de forma bem definida, surge no século XVIII um contorno nítido entre as duas esferas. Delimitação que obriga a considerar os homens como referidos a dois registros: o privado e o público. Essa fronteira constituía o indivíduo como ser social. Ou seja, entre cada uma das duas esferas de ação do indivíduo moderno delimitava-se modos de relação específicos, de modo que a noção de público se torna referida a uma região e um modo especial de sociabilidade. Na geografia do estar em público, a ação em público era uma questão de agir em certa distância do eu, da intimidade do outro, das circunstâncias, das necessidades e das idiossincrasias. Tal modo de sociabilidade, próprio das grande cidades europeias, era marcado pela valorização das convenções e da teatralização nos contatos sociais, modo de relação que atribuía aos homens a representação de papéis socialmente legíveis e a partir dos quais eles atuavam, permitindo um contato no espaço público que não colocava em jogo sua pessoalidade (Sennett, 1998).

Sennett (1998) aponta, entretanto, a relação entre o movimento de privatização, promovido pelo capitalismo industrial ao longo do século XIX, e uma certa mistifi- 
cação da vida material que começa a aparecer na classe burguesa de grande cidades como Paris e Londres. O movimento de privatização acaba por fazer com que as questões referidas ao indivíduo invadissem e redefinissem os sentidos do espaço público. O que ocorre é um fetichismo dos objetos materiais que passam a ser investidos de significado, denunciando os aspectos pessoais do indivíduo, que começava a ser entendido como dotado de uma interioridade singular. Assim, as vestimentas, atitudes e formas de apresentação deixam de funcionar como códigos de credibilidade e se tornam uma expressão da personalidade. Modo de entendimento e exercício da subjetividade demonstrado pelo individualismo romântico de Simmel, que surge no século XIX.

A análise de Simmel (1973) ressalta como o espaço público da métropole promoveu uma subjetividade altamente pessoal, quando a competitividade do sistema capitalista acaba por promover o refinamento e o enriquecimento das necessidades do público, e conduzir ao crescimento das diferenças pessoais no interior desse público. Em lugar da liberdade pessoal, a metrópole teria, assim, permitido o desenvolvimento das particularidades humanas. A extensão e a liberdade teriam catalisado um movimento constante de especialização de seus elementos sociais, institucionais, políticos, técnicos e individuais. Ou seja, quanto maior o contato com a heterogeneidade da multidão citadina e sua estrutura sociotécnica, mais forte se torna o movimento de diferenciação de um produto, um serviço e até mesmo do indivíduo: "A pessoa precisa enfrentar a dificuldade de afirmar sua própria personalidade no campo abrangido pelas dimensões da vida metropolitana" (Simmel, 1973, p. 22).

Com a valorização da dimensão psicológica, começa a se impor na sociabilidade do espaço público e no discurso político do século XIX o que Sennett (1998) denomina de 'regime da autenticidade', marcado pelo intenso desejo de autenticar a si mesmo, mostrando uma personalidade de acordo com o que realmente era. A impessoalidade, antes necessária na vida pública e política, se perde e as máscaras se tornam um falseamento da verdade. É o que Sennett (1998) chama de uma tirania da intimidade, de quando a complexidade da realidade social é enfrentada em termos psicológicos e gradualmente o eu passa a definir as relações sociais.

Respondendo à fidedignidade do modo como cada um se apresenta e se representa na vida online, o eu tem que se colocar diante da exigência de transparência e de autenticidade tal como o regime tratado em Sennett (1998). O conteúdo imaterial objetivado, seja por fotos, descrições, depoimentos ou comunidades, assume no Orkut a expressão de verdade sobre o sujeito. Um artifício de desvelamento e de denúncia da dimensão subjetiva, até então invisível, é agora objetivado de uma nova forma. Assim, o espaço público do Orkut se torna o lugar da verdade, onde o sujeito que fala deve coincidir com o sujeito dono do enunciado, livre de qualquer máscara ou falseamento. Relatado em $\underline{O \text { orkut me fez }}$ abrir os olhos! (19.620 membros) e Descobri quem vc é pelo orkut $\mathbb{R}$ (15.501 membros):

Você tem um (a) amigo (a) que você botava a mão no fogo por ele (a). Achava que a conhecia muito bem e depois de adicioná-la ou encontrá-la no orkut ficou surpreso com o perfil, fotos, comunidades ou amigos dele (a). Então esta é a sua comunidade, relate suas descobertas.

$\mathrm{Na}$ tentativa de fugir do imperativo da fidedignidade e do enquadramento identitário, os participantes passam a se inscrever e se desdobrar em mais de um perfil, dando origem aos chamados perfis fakes. Desdobramento que acaba por propiciar o exercício, a associação e a realização de aspectos antes mantidos ocultos ou escondidos. Dupla Personalidade no Orkut (3.786 membros):

Vc também tem dupla personalidade no Orkut??? Tem uma identidade verdadeira onde estão seus amigos da escola, do trabalho e a família e que não poderiam entender os seus desejos mais perversos, mais exóticos ou absurdos??? Não podemos mostrar realmente quem somos?!?! Temos que usar fotos pela metade, sem rosto ou sem detalhes... Se vc não pode se liberar perante essa sociedade hipócrita, aqui é o seu lugar! aqui vc pode o que quiser! Eu tenho dupla personalidade no Orkut e vc?? [grifo nosso]

$\mathrm{Na}$ medida em que cria um espaço comum de conexão e de comunicação de todos para todos, a principal característica do Orkut é produzir visibilidade. Sibilia $(2002,2003)$

é um dos muitos autores na atualidade que exploram as novas tecnologias de comunicação seguindo a linha de denúncia do esvaziamento ou reconfiguração da tradicional dicotomia entre público e privado (Dealtry, 2007; Franco Ferraz, 2001). A partir da análise dos diários íntimos na Internet (os chamados weblogs), a autora mostra como o espaço aberto das cenas comunicacionais contemporâneas se transforma em um lugar de exposição do que outrora ficava reservado à esfera privada, da intimidade e do secreto. A escrita dos diários íntimos, que costumava ser uma prática solitária nos séculos XVIII e XIX, se instala hoje no limiar da publicidade total. Diversos fenômenos contemporâneos, como os reality shows na televisão, a forte presença da produção documental no cinema, o sucesso das autobiografias, a difusão dos dispositivos de vigilância eletrônica, além das composições entre arte, arquitetura e tecnologia, revelam um cotidiano profundamente, exposto, olhado, documentado, publicizado, vigiado, espreitado.

Fenômeno que abarca a comunidade online do Orkut. Palavras como fuçar, xeretar, olhar, vasculhar, visitar, invadir e vigiar expressam um modo de uso que se 
tornou uma marca do site, como vemos em comunidades como: Eu sei que você fuça meu orkut (740.252 membros), Tem gente xeretando meu orkut (71.172 membros), Me vigiam pelo Orkut!!! (9.376 membros), Eu vasculho o Orkut alheio! (168.546 membros); Minha vida é um orkut aberto (20.887 membros); Quer privacidade? Sai do orkut (75.991 membros) ou Não quer visita? Saia do orkut! (11.397 membros) ${ }^{6}$. Trazem para a discussão a questão da visibilidade, da exposição de si e da quase impossibilidade de privacidade na rede. Onde os conteúdos que parecem estar em jogo são justamente os referidos a uma pessoalidade e abrem espaço para análises que ressaltam a supremacia do olhar do outro no processo de significação de si na atualidade (Bruno, 2004).

Os atravessamentos e reconfigurações entre os polos que costumavam organizar a vida social moderna são apontados como um dos principais efeitos das tecnologias contemporâneas. Para Thompson (1998) as mudanças sofridas na separação do par público versus privado, podem ser relacionadas ao advento e difusão da imprensa nas capitais europeias do século XIX. Quando as tecnologias de mídia - como jornais, revistas, rádio e televisão - assumem um caráter decisivo de publicidade e visibilidade, tornando as mensagens visíveis e verificáveis a uma multiplicidade de indivíduos que podem estar situados em contextos dos mais diversos.

Com base nos efeitos da publicidade televisiva no exercício político representacional, Thompson (1998) coloca que o vazamento é um dos maiores riscos trazidos pela mídia. $\mathrm{O}$ termo se refere a uma falha no esforço de manter na região de fundo do comportamento privado, informações ou condutas que o sujeito deseja esconder. De modo que a visibilidade produzida pelas mídias acaba por gerar uma dificuldade na negociação entre as duas esferas. O que pode ser visto em comunidades como Descobri pelo Orkut (130.605 membros), ou O Orkut me conta Tudo!!! (12.729 membros); $\mathrm{Meu}$ Orkut Me Condena (16.604 membros); Fiquei sabendo pelo orkut!!! (6.926 membros).

A partir do movimento de publicização de si, o site se transforma em ferramenta de desvelamento sobre aquilo que se refere ao outro e a si mesmo. Nesse processo, o conteúdo imaterial veiculado na página pessoal passa a servir de recurso em processos de identificação, verificação e até mesmo de estranhamento na relação com o outro. O "regime de visibilidade" promovido pelo Orkut acabaria por reconfigurar a distinção entre exterioridade e interioridade, público e privado, aparência e essência, sujeito e objeto. Habitar o espaço online da comunidade significa transformar as virtualidades em coletivo, o compartilhar de conteúdos antes invisíveis; o que abre a possibilidade de um novo sentido sobre elas, deslocamento exemplificado em Sou normal. descobri no orkut (42.357 membros). Enquanto a psi- quiatria faz de nossas estranhezas, doenças, o Orkut, na medida em que possibilita abri-las, permite fazer delas, normalidade:

Vc faz coisas que pensava não serem normais... Tem algumas manias que sentia até vergonha de falar... Pensava que só vc tinha certos tipos de amigos, de mãe, família... Achava que tinha feito coisas na infância que ninguém havia feito ou faz... E na escola, na facul, nas baladas, então... vixii, cada coisa que às vezes se perguntava: "Será que, realmente, eu sou normal?" Mas... vc, simplesmente, começa a achar no Orkut várias comunidade que jamais pensou que existisse. Descobre que, ñ só uma como, milhares de pessoas fazem as mesmas coisas, tem os mesmo tipo de amigos, de parentes, bichos, manias, infância, gostos... Pois é, você é normal!!!!

A dificuldade de fechamento pode ser vista também nas relações amorosas. Incontáveis são os depoimentos, histórias e comunidades que relatam a questão do ciúme, de quando o par se transforma em muitos dentro da rede pública da comunidade. São comuns e numerosas as comunidades que tratam do tema: Orkut me dá crise de ciúmes (49.434 membros), Namoro + Orkut $=$ Brigas 24h! (23.940 membros), Orkut destrói relacionamentos (22.634 membros), Já brigamos por causa do Orkut (11.478 membros), Orkut causa Ciúmes (64.919 membros).

"Um ator é também e sempre uma rede" (Law, 1992, p.2). Tornar-se um ponto na rede significa, irremediavelmente, simplificar, transformar a complexidade em um elemento fechado, liso e sem arestas para que, assim, ele possa ser reconhecido e possa circular. $\mathrm{Na}$ versão $\underline{\text { beta }}^{7}$ do sujeito, o perfil deve ser constantemente atualizado e mantido sempre em sintonia com os fatos e acontecimentos da realidade offline. Recuero (2003) demonstra o mesmo movimento nos seus estudos sobre os diários íntimos ou $\underline{b l o g s}$. Na tentativa de assegurar a sua própria autenticidade, os indivíduos são chamados a se confirmar e reafirmar, no esforço constante de manter a coerência em um constante movimento de tessitura entre as duas realidades. Entre o fato e o feito, o movimento contínuo de tradução na realidade online pressupõe que se escreva e reinscreva frequentemente nas páginas pessoais.

Mas que aspectos tornar visível no enquadramento da subjetividade em tela? Conforme afirmam Callon e Law (1997), não existe algo mais negociável do que as fronteiras entre os polos. Nesse movimento de mediação, não se pode afirmar que ocorra um aniquilamento do secreto, livre de qualquer negociação ou produção. Dar visibilidade a alguns aspectos pressupõe colocá-los em cartaz, em cena, enquanto outros são deixados à sombra. Mesmo que estes estejam sempre na iminência de escapar ou vazar. Comunidades como: No orkut todo mundo é bonito!! (1.202 membros), Todo mundo é perfeito no 
orkut (637 membros), Todo mundo é feliz no orkut (410 membros); No orkut todo mundo é modelo (41.506 membros) mostram como o movimento de tradução de si assume uma conotação de falseamento e artificialidade diante da exigência de autenticidade. Quem ser quando o eu assume a multiplicidade da realidade hipertextual por meio de fotos, depoimentos, recados, fãs, amigos, comunidades? Distorção ou manipulação que responde a lógica stay beautiful ${ }^{8}$ de ser. Momento em que o sujeito é chamado a se representar e se tornar um ponto no coletivo, tal representação de si mesmo se faz sempre falha, manipulável, mutável, infiel, torta e retorcida. Movimento de delimitação que não se encerra no espaço-tempo presente, mas que responde também a um projeto, um futuro diante da ordem do desejo e da idealização.

O processo de mediação entendido como tradução implica sempre e invariavelmente em um processo de traição (Law, 1999). A exigência de correspondência, autenticidade e transparência só seria possível na comunicação pretensamente exata, reta e não deformada. Ou seja, na representação fiel diante da ausência de qualquer mediação. Na reflexão sobre a crise da representação política, Latour (2004) defende que a exigência de uma verdade transparente e direta na representação de um coletivo é impossível.

O trabalho de representação tem por objetivo transformar os muitos em um, e pode ser entendido como o meio através do qual se transforma uma multiplicidade em uma unidade. Com base na composição heterogênea dos atores, na rede a ideia de unidade, fechamento e coerência tornam-se frágeis. Surge uma espécie de enquadramento impossível do aspecto coletivo do elemento individual. Como um ponto da rede e uma rede em si mesmo, o sujeito, ao se representar, esforça-se em reunir e manter unidas as partes ou elementos heterogêneos que o constituem. Composição ou agregado que tem como palavra de reagrupamento seu nome próprio.

Diante disso, no exercício de representação são absurdas tanto a exigência de transparência quanto a exigência de obediência. $\mathrm{E}$ a impraticabilidade deste círculo, cai em um incessante trabalho de repetição onde mentira e verdade, autonomia e heteronomia se fazem sempre presentes. Para fazer o círculo fechar é preciso, constantemente, um trabalho de cercar, apreender e reproduzir, traçando sempre provisoriamente o seu invólucro. Para representar a multiplicidade do estado de coisas de um agrupamento, é preciso que haja uma produção contínua desse círculo (Latour, 2004). Na tentativa de reunir todos os seres, coisas, datas e lugares em um nome, a unidade de si midiatizada se torna pública, aberta e coletiva, fazendo com que a suposta autenticidade e fidedignidade estejam sempre por um fio.

\section{A caminho de uma subjetividade entendida como coletiva}

O conceito de mediação, segundo as proposições de Latour (1994a, 1994b, 2004) e dos autores da Teoria Ator-Rede (Callon \& Law, 1997; Law, 1992, 1999), se refere ao movimento de "tradução" desenvolvido por Serres (1994) para designar deslocamento, invenção. Ou seja, a criação de uma ligação que não existia antes e que em algum nível modifica os dois elementos ou agentes do quadro de ação considerado. Entendido como um processo de tradução tal como postulado pelo autor, o movimento de mediação se refere ao processo mesmo de composição ou de produção dos elementos envolvidos e mobilizados no plano de interação. O processo de mediação promovido pelos dispositivos identificatórios do Orkut não seria, assim, entendido como simplesmente um movimento de reprodução do real. A relação de mediação com a interface comunicacional ultrapassa o esquema de ação corte e colagem, aquilo que Latour (1994b) chama de informação double click por alusão ao mouse do computador.

Sibilia (2007) propõe que, para além de um aprofundamento quantitativo do narcisismo e voyeurismo, o movimento de visibilidade que a intimidade adquire em espaços como o Orkut, fermenta uma nova forma de subjetivação. Tornar-se objeto passível de conhecimento e de ser apreendido pelo outro por meio da tela implica, ao mesmo tempo, tornar-se aberto e acessível, aumentando a superfície de contato e facilitando as trocas. Aquilo que era tomado na ordem do privado - a intimidade - passa por um movimento de publicização, de modo que as práticas de exposição atuais promoveriam um esvaziamento da ideia de indivíduo como dotado de uma interioridade. A aposta de autores como Sibilia (2007), Bruno e Pedro (2005) é de que o movimento promovido pela mediação tecnológica não trata da exteriorização de uma interioridade, mas antes de uma subjetividade que agora se constitui no ato mesmo de se fazer visível, acessível ao outro.

Antes de dizer que a subjetividade se faz, hoje, no lugar do aparente e do superficial, é preciso considerar que sua produção sempre se deu no lugar da relação, no lugar do contato e da interação. Não só da interação imediata dos humanos entre eles mesmos, mas principalmente da interação que estabelecemos com os objetos técnicos de nossa época. Tal como no trabalho historiográfico de Chartier $(1991,1998)$ sobre a prática da leitura silenciosa, retratando como a escrita e a prática solitária, recolhida e individual da leitura participaram do desenvolvimento da ideia de intimidade nos séculos XVIII e XIX.

O site e seus dispositivos tecnológicos se constituem, na atualidade, como mais dos muitos artifícios 
por meio dos quais a subjetividade se produz. Nesse sentido, poderia-se afirmar que o Orkut participa promovendo uma nova forma de exercício de si. O que na modernidade era entendido como uma unidade dotada de uma interioridade e profundidade, hoje é entendido como múltiplo, aberto e distribuído. O que se pretende defender é que a mudança na expressão que o sujeito assume ocorre a partir dos diferentes objetos técnicos com os quais ele se relaciona. A subjetividade, assim entendida como coletiva, não é algo que transborda através dos diversos utensílios sintéticos. A dimensão psicológica do humano nunca ocupou tanto espaço porque nunca se teve uma rede de artefatos tão complexa através da qual pudesse se compor.

\section{Notas}

1 Criado em janeiro de 2004, o Orkut pode ser considerado a primeira comunidade virtual a se difundir efetivamente no Brasil. O programa foi criado por Orkut Buyokkokten, engenheiro da empresa americana Google - empresa que administra o site.

2 Descrição dada pelos administradores e presente na primeira página do site: http: // www.orkut.com.

3 Há muitos erros, do ponto de vista da norma culta da língua, no Orkut e na descrição das comunidades que foram trazidas ao longo da discussão. Contudo, há um estilo de escrita, estilo que julgou-se interessante manter, que faz uso do "C" por "se", "pq" por "porque", "vc" por "você", "q" por "que". Uma escrita com base na fonética das palavras que mostra o jeito oralizado da comunicação no site.

4 Os dados referidos ao número de membros das comunidades trazidas foram retirados no trabalho de pesquisa de campo feita no site, em agosto de 2007. Todas as comunidades podem ser achadas acessando o site http: // www.orkut.com

5 Sobre o caráter identitário do Orkut ver: Barbosa, A. da S. N. (2008). Os perfis identitários na comunidade virtual do Orkut. Dissertação de mestrado. Comunicação, UNIP, SP e Silva, C. R. (2008). Imagem e Identidade no ciberespaço: a significação social dos perfis do Orkut. Dissertação de Mestrado. Comunicação e Semiótica, PUC/SP.

6 Marcado pela presença constante do olhar do outro, a comunidade virtual é usualmente comparada com o programa de reality show Big Brother Brasil. Programa televisionado todo ano pela maior emissora do país, é um jogo onde doze pessoas são colocadas dentro de uma casa e convivem isolados e vigiados 24 horas por dia. Para mais ler: Albuquerque, L. S. G. (2005). Mídia e transformação da intimidade na atualidade: as implicações subjetivas da exposição da vida intima nos reality shows. Dissertação de Mestrado nãopublicada. Universidade Federal do Rio de Janeiro, Instituto de Psicologia. Rio de Janeiro, RJ.

7 Alusão ao estado dos softwares em versão beta, que, como o Orkut, ainda estão em fase de construção.

8 A expressão em inglês é usualmente utilizada pelos administradores do Orkut em informes, anúncios e advertências dentro da comunidade. Funciona como uma espécie de jargão do site. Na versão em português se traduziu em: "Mantenha o Orkut bonito"

\section{Referências}

Albuquerque, L. S. G. (2005). Midia e transformação da intimidade na atualidade: as implicações subjetivas da exposição da vida íntima nos reality shows. Dissertação de Mestrado, Instituto de Psicologia, Universidade Federal do Rio de Janeiro, Rio de Janeiro, RJ.

Barbosa, A. da S. N. (2008). Os perfis identitários na comunidade virtual do Orkut. Dissertação de Mestrado, Comunicação. Universidade Paulista, São Paulo, SP.

Bauman, Z. (2001). Modernidade líquida. Rio de Janeiro: Jorge Zahar Ed.

Bauman, Z. (2005). Identidade: entrevista a Benedetto Vecchi. Rio de Janeiro: Jorge Zahar Ed.

Bruno, F. G. (2004). Máquinas de ver, modos de ser: visibilidade e subjetividade nas novas tecnologias de informação e de comunicação. Revista FAMECOS: mídia, cultura e tecnologia, 24, 110-124.

Bruno, F. G. \& Pedro, R. (2005/setembro). Entre aparecer e ser: tecnologia, espetáculo e subjetividade contemporânea. Trabalho apresentado no IV Encontro dos Núcleos de Pesquisa da Intercom, Sociedade Brasileira de Estudos Interdisciplinares da Comunicação, UERJ, Rio de Janeiro. Acesso em 20 de maio, 2009, em http:/www.intercom.org.br/papers/ nacionais/2005/errata/RosaPedroFernandaBruno.pdf

Callon, M. \& Law, J. (1997). L'irruption des non-humains dans lês sciences humaines: quelques leçons tirées de la sociologie des science et des techniques. In B. Reynaud (Ed.), Les limites de la rationalité: Lês figures du collectif (pp. 99-118). Paris: La Découverte.

Chartier, R. (1991). As práticas da escrita. In P. Áries \& R. Chartier (Orgs.), História da vida privada. Da Renascença ao Século das Luzes (H. Feist, Trad., Vol. 3, pp. 113-167). São Paulo: Companhia das Letras.

Chartier, R. (1998). A aventura do livro: do leitor ao navegador (R. Moraes, Trad.). São Paulo: Fundação Editora da UNESP (Prismas).

Constant, B. (1985). Da liberdade dos antigos comparada à dos modernos. Filosofia política, 2, 09-25.

Dealtry, G. F. (2007). Diante de janelas: fronteiras entre público e privado na (pós) modernidade. Estudos e Pesquisas em Psicologia, 7(2), 188-197.

Franco Ferraz, M. C. (2001). Reconfigurações do público e do privado: mutações da sociedade tecnológica contemporânea. Revista Famecos, 15, 29-43.

Goffman, E. (2005). Manicômios, prisões e conventos. São Paulo: Perspectiva.

Jovchelovitch, S. (2008). Os contextos do saber: representações, comunidades e cultura. Petrópolis, RJ: Vozes.

Latour, B. (1994a). Une sociologie sans objet? Remarques sur l'interobjectivité. Socilogie du travail, 36(4), 587-607.

Latour, B. (1994b). On technical mediation: philosophy, sociology, genealogy. Commom Knowledge, 3(2), 29-64.

Latour, B. (1997, 14 de agosto). O sociólogo Bruno Latour desafia os partidários da tese da sociedade do espetáculo. Folha de São Paulo, pp. 5-7.

Latour, B. (2004). Se falássemos um pouco de política? Política e Sociedade: Revista de Sociologia Política, 4, 11-41.

Law, J. (1992). Notes on the theory of actor network: ordering, strategy and heterogeneity. Departamento de Sociologia, Universidade de Lancaster. Acesso em 20 de maio, 2009, em http:// www.lancs.ac.uk/fass/sociology/papers/law-notes-on-ant.pdf 
Law, J. (1999). Traduction/trahison: notes on ANT. Departamento de Sociologia, Universidade de Lancaster. Acesso em 20 de maio, 2009, em http://www.lancs.ac.uk/fass/sociology/ papers/law-traduction-trahison.pdf

Lemos, A. (2002). Agregações eletrônicas ou comunidades virtuais? Análise das listas Facom e Cibercultura. Revista 404NotFound, ano 2, 14. Acesso em 20 de maio, 2009, em http://andrelemos.info/404nOtF0und/404_14.htm

Recuero, R. C. (2001). Comunidades virtuais: uma abordagem teórica. Trabalho apresentado no V Seminário Internacional de Comunicação, no GT de Comunicação e Tecnologia das Mídias, promovido pela PUC-RS, Porto Alegre. Acesso em 20 de maio, 2009, em http://pontomidia.com.br/raquel/teorica.pdf

Recuero, R. C. (2003). Weblogs, webrings e comunidades virtuais. Revista 404 NotFound, Edição 31. Acesso em 20 de maio, 2009, em http://pontomidia.com.br/raquel/webrings.pdf

Sawaia, B. B. (2007). Comunidade: a apropriação científica de um conceito tão antigo quanto a humanidade. In R. H. F. Campos (Org.), Psicologia social comunitária: da solidariedade à autonomia (pp. 35-53). Petrópolis, RJ: Vozes.

Sennet, R. (1998). O declínio do homem público: as tiranias da intimidade (L. A. Watanabe, Trad.). São Paulo: Companhia das Letras.

Serres, M. (1994). Atlas. (J. Paz, Trad.). Lisboa: Instituto Piaget.

Serres, M. (1999). Novas tecnologias e sociedade pedagógica - uma conversa com Michel Serres [versão eletrônica]. Interface, 4(6), 129-142. Acesso em 20 de maio, 2009, em http:// www.interface.org.br/revista6/entrevista1.pdf

Sibilia, P. (2002). O homem pós-orgânico: corpo, subjetividade e tecnologias digitais. Rio de Janeiro: Relume Dumará.

Sibilia, P. (2003). Os diários íntimos na Internet e a crise da interioridade psicológica. In A. Lemos \& P. Cunha (Orgs.), Olhares sobre a cibercultura (pp. 139-152). Porto Alegre: Editora Sulina.

Sibilia, P. (2007). O show do eu: subjetividade nos gêneros confessionais da Internet. Rio de Janeiro: UFRJ, Escola de Comunicação.

Silva, C. R. (2008). Imagem e Identidade no ciberespaço: a significação social dos perfis do Orkut. Dissertação de Mestrado. Comunicação e Semiótica, PUCSP, São Paulo, SP.
Simmel, G. (1973). A metrópole e a vida mental. In O. G. Velho (Org.), O fenomeno urbano (pp. 11-25). Rio de Janeiro: Zahar.

Thompson, J. B. (1998). A mídia e a modernidade: uma teoria social da mídia (W. O. Brandão, Trad.). Petrópolis, RJ: Vozes.

Vernant, J. P. (1968). Origens do pensamento grego. São Paulo: Difel.

Recebido em: 27/05/2009

Aceite final em: 10/08/2010

Carla Neves é Mestre pelo Programa de Pós-Graduação em Psicologia da Universidade Federal do Rio de Janeiro. Atualmente atua como psicóloga na Universidade Federal Rural do Rio de Janeiro - UFRRJ e cursa o doutorado na linha de Processos Psicossociais e Coletivos do Programa de Pós-Graduação em Psicologia da UFRJ. Endereço: Rua Conde de Bonfim, 782/18. Tijuca. Rio de Janeiro/RJ, Brasil. CEP 20530-002. Email: carlaneves.psi@gmail.com

Francisco Teixeira Portugal é Doutor em Psicologia pela PUC-Rio (2002). Atualmente é professor do Programa de Pós-Graduação em Psicologia da Universidade Federal do Rio de Janeiro - UFRJ. Endereço: Programa de Pósgraduação em Psicologia. Instituto de Psicologia da UFRJ. Avenida Pasteur, 250. Pavilhão Nilton Campos. Praia Vermelha. Rio de Janeiro/RJ, Brasil. CEP 22290-240. Email: fportugal@ufrj.br

\section{Como citar:}

Neves, C. \& Portugal, F. T. (2011). A dimensão pública da subjetividade em tempos de Orkut. Psicologia \& Sociedade, 23(1), 15-23. 